\title{
Analyzing the Usage of IT in SMEs
}

\author{
Sona Mardikyan \\ Boğaziçi University, Istanbul, Turkey
}

\begin{abstract}
Nowadays, rapid changes in information technology (IT) force enterprises to adapt new developments. IT is critical to the success of most businesses especially small and medium sized enterprises (SMEs). In recent years, the information technologies are started to be used frequently by SMEs in Turkey but unfortunately the usage has not reached to desired levels yet. The aim of this study is to investigate the purposes of the IT usage in SMEs and put forward the key factors affecting the level of their IT usage. To be able to evaluate the IT usage, a survey questionnaire was prepared and conducted to 112 SMEs in Istanbul. Data were analyzed by Descriptive, Independent T-Test, One-Way ANOVA and Multiple Regression Analyses. Findings are almost consistent with the previous researches. The study states that most of SMEs uses IT for their basic needs but they show the tendency to use it for more advanced activities. Moreover, there are significant differences in the IT usage of the companies operating in different sectors. The study also highlights that strong IT infrastructure, higher number of workers, giving importance to IT training, finding more purposes to use IT, and functioning in IT sector are important factors that positively affect IT usage.
\end{abstract}

Keywords: Information Technology (IT); Small and Medium Sized Enterprises (SMEs); IT Usage; Factors

\section{Introduction}

In information societies which consist of developed and developing countries, economic priorities are given to information production and usage. Information technology (IT) is critical to the success of most businesses. Small and medium sized enterprises (SMEs) are among the most dynamic actors with their quick adaptation skills on both taking decision and implementation, and at this point they are at a more advantageous place with regard to their competitors. But unfortunately, they are generally not using IT fully in their business activities. In recent years, there has been a widespread interest in understanding the factors that affect IT usage in SMEs. Maguire et al. (2007) indicated that SMEs can gain competitive advantage through the use of information and communications technology. The key variables and challenges facing organizations in harnessing information and communications technology for growth are discussed in recent researches (Matthews, 2007; Bayo-Moriones and Lera-Lopez, 2007). According to Esselaar et al. (2007) the use of information and communications technology increases the labor productivity. Süygün (2007) pointed out that competitors are one of the important external factors considered by SMEs in IT adoption. IT usage increases company's competitive advantages as well as its efficiency in international market. Moreover, IT training given to employees has positive effect on IT usage of employees. IT can be used to support the business relation with suppliers and customers. External, organizational, and technological factors are investigated by Ang et al. (2001) to put forward their impact on the use of IT to support total quality management. In respect of the research made by Kutlu and Özturan (2008), the increased use of IT in SMEs is

Copyright (C) 2010 Sona Mardikyan. This is an open access article distributed under the CreativeCommons Attribution License unported 3.0, which permits unrestricted use, distribution, and reproduction in any medium, provided that original work is properly cited. Contact author: Sona Mardikyan, email: mardikya@boun.edu.tr 
mainly for operational and routine tasks, positive attitude of managers produce high levels of success in IT adoption, and expected benefits of IT is one of the main factors for IT implementation decisions.

A number of authors confirm that business value from SMEs adopting the Internet and Internet related technologies is growing day by day. The main issues and barriers with regard to the level of Internet and ecommerce adoption and activity are investigated by Stansfield and Grant (2003). Kula and Tatoğlu (2003) demonstrated that reasons for internet usage of SMEs are mostly for external communication and gathering information for market and product research. According to Lohrke et al. (2006) an important benefit of the internet usage is reducing SMEs' transaction costs. In another research (Koh and Maguire, 2004) e-business and knowledge management approaches used by SMEs in the UK are investigated. Findings showed that they have increasingly applied e-business activities but knowledge management is a relatively new concept and most of them do not use knowledge management applications. In the research by Kaynak et al. (2005) the factors on e-business and ecommerce information technology adoption decisions made by SMEs are investigated.

In Turkey SMEs are very important businesses, because an important percentage of Turkish economy is formed with SMEs. But unfortunately, there is not enough research about IT usage of SMEs. In order to promote their IT usage level, it is important to understand the determinanats and key variables of IT usage. The objective of this study is to investigate these factors and determine their level of influence on IT usage in SMEs. In Section 1, a brief review of the literature survey on IT usage is given. Section 2 covers the research methodologies used in the study. The results of the analyses are presented and discussed in Section 3 and, finally conclusions and some recommendations are put forward in Section 4 .

\section{Methodology}

The objective of this study is to find out the important purposes SMEs are using ITs and investigate how some general characteristics of the companies together with their IT infrastructures and IT perspectives change with their IT usage level. Under the guideline of the literature survey, some general characteristics of the companies, IT infrastructures, IT perspectives, IT training approaches, sectors, IT usage aims and IT usage level in terms of internet usage, web page usage and software usage levels are taken into account as the variables of the study. The data were gathered using a questionnaire.

The questionnaire included 40 questions of which 3 were open ended such as company's annual giro, company age, company size (number of worker). There was 1 closed ended question for the company's sector (textile, machine, food, construction, IT, and others). To describe IT infrastructure of company there were 5 questions; IT usage year, number of computers, intranet usage (yes/no), corporate mail ownership (yes/no), and web site ownership (yes/no). The following 9 questions were grouped under two headings such as company's IT training approach (1 question about the importance of the IT training given to employees), and importance of IT usage aims (reduce cost, improve competitiveness, time saving, improve product and service quality, improve sales, improve overall productivity of the company, provide data security and integrity, increase customer satisfaction). All of these 9 questions were 5-point Likert scale (5: Strongly agree, 1: Strongly disagree). In some analysis, to be able to specify a single variable for IT usage aims, the average of the related questions were calculated.

In order to measure IT usage of a company, internet usage level, web page usage level and software usage level of that company may be evaluated. For this reason, there were three groups of questions related to these components. Internet usage level component includes 7 questions about the frequency of internet usage for different 
purposes (banking, e-mail, e-commerce, advertising, market research, training, and news). Web page usage level component included 7 different purposes (advertising, image enhancement, e-commerce, order activities, customer relationship, vendor relationship, international market relationship) of having a web site and questions were related to the frequencies of their usage. Software usage level component included 8 questions about the frequency of software (MS Office, B2B and B2C applications, accounting programs, ERP applications, CRM applications, CAD/CAM applications, database applications and functional IT applications) usage. All of these 22 questions were 5point Likert scale (5: most often, 1: never). Three group averages were calculated and assigned to internet usage level, web page usage level and software usage level variables respectively. To obtain a single variable for IT usage the average of these three components was calculated. In some analyses internet usage level, web page usage level and software usage level variables were used separately as target variables. However in two analyses, IT usage variable was used as a single target variable.

The survey was conducted in spring 2009 to 180 different SMEs located in Istanbul. 112 questionnaires were returned. During the sample size selection process, great importance was given to obtain variety in company size and company sector such as textile, machine, food, construction, IT, and others. Questionnaires were answered by only one authorized employee from each company. Collected data were entered to SPSS 17.0 for further statistical analysis.

The following analyses were applied to the data.

- Descriptive Statistics for the variables of the study.

- Independent Samples T-Test in order to analyze the relationship between IT usage and company's characteristics. For this purpose, separate analyses were conducted on the internet usage, web page usage and software usage levels of companies having different IT infrastructure characteristics.

Hypothesis:

○ There are no statistically significant differences in the internet usage, web page usage, and software usage levels between companies using intranet and companies not using intranet.

- There are no statistically significant differences in the internet usage, web page usage, and software usage levels between companies having corporate mail and companies not having corporate mail.

- There are no statistically significant differences in the internet usage, web page usage, and software usage levels between companies having web site and companies not having web site.

- One-Way ANOVA Test to differentiate IT usage among sectors. Therefore, a one-way ANOVA test was conducted on IT usage of the companies functioning in different sectors. If significant differences are to be found, the Tukey HSD multiple comparison test is to be used to determine differences between sectors.

Hypothesis:

- There are no statistically significant differences in the IT usage between companies functioning in different sectors.

- Multiple Regression Analysis was undertaken in an attempt to investigate variables that have significant effects on the IT usage of SMEs. The dependent variable of the analysis is the IT usage and the independent variables are giro, 
company age, company size, dummies for company sector, IT usage year, number of computers, intranet usage, corporate mail ownership, web site ownership, IT training approach, and IT usage aim as a single variable.

\section{Results}

Descriptive Statistics: Minimum, maximum and mean values of the variables related to annual giro, company age, company size, IT usage year, number of computers, It training approach, IT usage aims, internet, web page and software usage levels are given in Table 1 . The results highlight that great importance is given to the IT training and to all the IT usage aims specified in the study but especially to time saving. SMEs in Turkey uses internet mostly for sending and receiving e-mails, reading news, for banking operations and for market research. The most preferred reasons to use web page are advertising, strengthening the company image and customer relationship. According to the results, almost all of the SMEs are using MS Office applications very frequently. Additionally, they also benefit from the accounting applications and functional IT applications. As it is understood from these results, most of SMEs in Turkey uses IT for their basic needs which are required to continue their business. More advanced activities like enterprise resource planning, customer relationship management, ecommerce, and international market relationship are not used extensively.

Table 1: Descriptive statistics for variables of the study

\begin{tabular}{|l|c|c|c|}
\hline & Minimum & Maximum & Mean \\
\hline Giro & 50,000 & $300,000,000$ & $9,087,214.29$ \\
\hline Company age & 1 & 23 & 13.74 \\
\hline Company size & 5 & 200 & 45.94 \\
\hline IT usage year & 1 & 30 & 11.47 \\
\hline Number of computers & 5 & 45 & 10.54 \\
\hline IT training approach & 1 & 5 & 3.99 \\
\hline IT usage aims: & & & \\
\hline Reduce cost & 1 & 5 & 3.73 \\
\hline Improve competitiveness & 1 & 5 & 3.76 \\
\hline Time saving & 1 & 5 & 4.27 \\
\hline Improve product and service quality & 1 & 5 & 3.49 \\
\hline Increase sales & 1 & 5 & 3.53 \\
\hline Improve overall productivity & 1 & 5 & 3.87 \\
\hline Provide data security and integrity & 1 & 5 & 3.99 \\
\hline Increase customer satisfaction & 1 & 5 & 3.41 \\
\hline Internet usage levels: & 1 & 5.4 & \\
\hline Banking & 1 & 5 & 3.41 \\
\hline e-mail & 1 & 5 & 3.51 \\
\hline e-commerce & 1 & 5 & 3.91 \\
\hline Advertising & 1 & 5 & \\
\hline Market research & 1 & 5 & \\
\hline Training & 1 & 5 & \\
\hline News & 1 & 5 & \\
\hline & 1 & 5 & \\
\hline
\end{tabular}




\begin{tabular}{|l|c|c|c|}
\hline Web page usage levels: & & & \\
\hline Advertising & 1 & 5 & 2.89 \\
\hline Image enhancement & 1 & 5 & 2.89 \\
\hline e-commerce & 1 & 5 & 1.77 \\
\hline Order activities & 1 & 5 & 1.69 \\
\hline Customer relationship & 1 & 5 & 2.46 \\
\hline Vendor relationship & 1 & 5 & 2.03 \\
\hline International market relationship & 1 & 5 & 1.75 \\
\hline Software usage levels: & & & \\
\hline Ms Office & 1 & 5 & 4.65 \\
\hline B2B_B2C & 1 & 5 & 2.21 \\
\hline Accounting applications & 1 & 5 & 3.77 \\
\hline ERP applications & 1 & 5 & 1.89 \\
\hline CRM applications & 1 & 5 & 1.87 \\
\hline CAD/CAM applications & 1 & 5 & 2.15 \\
\hline Database applications & 1 & 5 & 2.27 \\
\hline Functional IT applications & 1 & 5 & 2.79 \\
\hline
\end{tabular}

In all the following analyses the significance level was selected as 0.05 .

Independent Samples T-Test: The results are summarized as follows.

- There are no significant differences in the web page usage level between companies using intranet and companies not using intranet. However, there are significant differences in the internet usage level and software usage level between companies using intranet and companies not using intranet. (Table 2)

Table 2: The t-test results for companies using intranet and companies not

\begin{tabular}{|c|c|c|c|c|c|r|}
\hline & Intranet & Mean & Std. Deviation & $\mathrm{t}$ & $\mathrm{df}$ & Significance \\
\hline \multirow{2}{*}{ Internet Usage Level } & no & 2.4485 & 1.00006 & -2.698 & 110 & .008 \\
\cline { 2 - 8 } & yes & 3.0851 & .87698 & & & \\
\hline \multirow{2}{*}{ Web Page Usage Level } & no & 2.0735 & 1.20712 & -.286 & 109 & .775 \\
\cline { 2 - 8 } & yes & 2.1995 & 1.73692 & & & \\
\hline \multirow{2}{*}{ Software Usage Level } & no & 2.4755 & .72992 & -4.610 & 110 & .000 \\
\cline { 2 - 8 } & yes & 3.3351 & .70428 & & & \\
\hline
\end{tabular}


- There are significant differences in the internet usage level, web page usage level and software usage level between companies having corporate mail and companies not having corporate mail. (Table 3 )

Table 3: The t-test results for companies having corporate mail and companies not having corporate mail

\begin{tabular}{|l|c|c|c|c|c|c|}
\hline \multirow{2}{*}{ Internet Usage Level } & Corporate Mail & Mean & Std. Deviation & $\mathrm{t}$ & $\mathrm{df}$ & Significance \\
\cline { 2 - 8 } & no & 2.5000 & .83991 & -4.134 & 110 & .000 \\
\hline \multirow{2}{*}{ Web Page Usage Level } & yes & 3.2198 & .87017 & & & \\
\cline { 2 - 7 } & no & .4357 & 1.00292 & -10.684 & 109 & .000 \\
\hline \multirow{2}{*}{ Software Usage Level } & yes & 2.9836 & 1.23480 & & & \\
\cline { 2 - 8 } & no & 2.8889 & .69551 & -3.100 & 110 & .002 \\
\hline
\end{tabular}

- $\quad$ There are significant differences in the internet usage level, web page usage level and software usage level between companies having web site and companies not having web site. (Table 4)

Table 4: The t-test results for companies having web site and companies not having

\begin{tabular}{|l|c|c|c|c|c|c|}
\hline \multirow{2}{*}{} & Web Site & Mean & Std. Deviation & $\mathrm{t}$ & $\mathrm{df}$ & Significance \\
\hline \multirow{2}{*}{ Internet Usage Level } & no & 2.5547 & .81268 & -3.289 & 110 & .001 \\
\cline { 2 - 8 } & yes & 3.1620 & .90872 & & & \\
\hline \multirow{2}{*}{ Web Page Usage Level } & no & .0000 & .00000 & -16.052 & 109 & .000 \\
\cline { 2 - 8 } & yes & 3.0633 & 1.07657 & & & \\
\hline \multirow{2}{*}{ Software Usage Level } & no & 2.9531 & .67665 & -2.225 & 110 & .028 \\
\cline { 2 - 8 } & yes & 3.3052 & .78577 & & & \\
\hline
\end{tabular}

The results show that SMEs having strong IT infrastructure have higher levels of IT usage with respect to internet, web page and software usage.
One-Way ANOVA Test: According to the ANOVA results shown in Table 5 there are significant differences in the IT usage of the companies in different sectors.

Table 5: ANOVA table for IT usage

\begin{tabular}{|l|r|r|r|c|l|}
\hline & Sum of Squares & df & Mean Square & F & Sig. \\
\hline Between Groups & 15.772 & 5 & 3.154 & 4.258 & .001 \\
\hline Within Groups & 77.776 & 105 & .741 & & \\
\hline Total & 93.547 & 110 & & & \\
\hline
\end{tabular}


According to the Tukey HSD test results given in Table 6:

- $\quad$ There are significant differences in IT usage of companies functioning in Food sector and those in IT sector.

- $\quad$ There are significant differences in IT usage of companies functioning in Construction sector and those in IT sector.

- There are significant differences in IT usage of companies functioning in IT sector and those in other sectors.

Table 6: Tukey HSD multiple comparison between group pairs

\begin{tabular}{|c|c|c|c|}
\hline SECTOR(i) & SECTOR(j) & Mean Difference (i-j) & Sig. \\
\hline \multirow[t]{5}{*}{ Textile } & Machine & -.10381 & .999 \\
\hline & Food & .41425 & .761 \\
\hline & Construction & .51273 & .656 \\
\hline & IT & -.70689 & .270 \\
\hline & Other & .11921 & .999 \\
\hline \multirow[t]{5}{*}{ Machine } & Textile & .10381 & .999 \\
\hline & Food & .51806 & .339 \\
\hline & Construction & .61655 & .289 \\
\hline & IT & -.60307 & .269 \\
\hline & Other & .22303 & .949 \\
\hline \multirow[t]{5}{*}{ Food } & Textile & -.41425 & .761 \\
\hline & Machine & -.51806 & .339 \\
\hline & Construction & .09848 & .999 \\
\hline & IT & $-1.12113^{*}$ & .002 \\
\hline & Other & -.29503 & .854 \\
\hline \multirow[t]{5}{*}{ Construction } & Textile & -.51273 & .656 \\
\hline & Machine & -.61655 & .289 \\
\hline & Food & -.09848 & .999 \\
\hline & IT & $-1.21962^{*}$ & .003 \\
\hline & Other & -.39352 & .751 \\
\hline \multirow[t]{5}{*}{ IT } & Textile & .70689 & .270 \\
\hline & Machine & .60307 & .269 \\
\hline & Food & $1.12113^{*}$ & .002 \\
\hline & Construction & $1.21962^{*}$ & .003 \\
\hline & Other & $.82610^{*}$ & .041 \\
\hline \multirow[t]{5}{*}{ Other } & Textile & -.11921 & .999 \\
\hline & Machine & -.22303 & .949 \\
\hline & Food & .29503 & .854 \\
\hline & Construction & .39352 & .751 \\
\hline & IT & $-.82610^{*}$ & .041 \\
\hline
\end{tabular}


Multiple Linear Regression Analysis: In this analysis, Stepwise Regression model was selected to overcome multicollinearity problem. According to the results summarized in Table 7 , the $F$ test of the model is found to be significant.

Table 7: Model summary and ANOVA ${ }^{\mathrm{b}}$ table

\begin{tabular}{|c|c|c|c|c|c|c|}
\hline Model & $\mathrm{R}$ & $\begin{array}{l}\mathrm{R} \\
\text { Square }\end{array}$ & $\begin{array}{l}\text { Adj. R } \\
\text { Square }\end{array}$ & SE Estimate & $\mathrm{F}$ & Sig. \\
\hline 7 & $.816^{\mathrm{g}}$ & .665 & .642 & .55141 & 29.239 & $.000 \mathrm{~g}$ \\
\hline
\end{tabular}

a) Predictors: (Constant), Web site, Intranet, IT training approach, IT sector, Company size, IT usage aim

b) Dependent Variable: IT_USAGE_AVG

Table 8 shows that the significant variables of the model are web site ownership, intranet usage, IT training approach, IT sector, company size, and IT usage aim. At the beginning of the study, it is supposed that there may be a positive relationship between IT usage level and company's giro, age, IT usage year and number of computers used. However this analysis shows that there are no significant relations between these variables.

\begin{tabular}{|c|c|c|c|c|c|}
\hline \multirow[b]{2}{*}{ Model } & \multicolumn{2}{|c|}{ Unstd. Coefficients } & \multirow{2}{*}{$\begin{array}{l}\text { Std. Coefficients } \\
\text { Beta }\end{array}$} & \multirow{2}{*}{$\mathrm{T}$} & \multirow[b]{2}{*}{ Sig. } \\
\hline & B & Std. Error & & & \\
\hline 7 (Constant) & .339 & .280 & & 1.211 & .229 \\
\hline Web site & 1.177 & .127 & .581 & 9.258 & .000 \\
\hline Intranet & .499 & .154 & .196 & 3.251 & .002 \\
\hline IT training approach & .116 & .047 & .148 & 2.443 & .016 \\
\hline IT sector & .502 & .156 & .192 & 3.216 & .002 \\
\hline Company size & .003 & .001 & .193 & 3.096 & .003 \\
\hline IT usage aim & .101 & .042 & .140 & 2.372 & .020 \\
\hline
\end{tabular}

a. Dependent Variable: IT_USAGE_AVG

In this model, all the coefficients have positive signs which indicate that they all have a positive affect on the IT usage of the SMEs. The value of $\mathrm{R}^{2}$ is 0.665 which indicates considerably strong relationship between the dependent and independent variables of the model. In other words, these variables together can describe the variability of the IT usage of SMEs at a level of $66.5 \%$ in the population. As a result, companies having a web site, using intranet technology, understanding the importance of IT training, functioning in IT sector, having more number of workers, and more purposes to use IT, have high level of IT usage.

\section{Conclusions}

The present study examines the important factors influencing the IT usage of SMEs. The data were collected through a questionnaire that was conducted in Istanbul.

Some of the findings of the study are parallel with the views of the previous researches. According to the results of the conducted analyses:

- SMEs mostly use information technologies in order to save time, increase efficiency of the company 
as well as simplify preserving, maintaining and processing data.

- They are aware of the importance of IT usage. They feel that they have to use information technologies to be able to survive in their market and reach the same position with their competitors.

- SMEs mostly use office programs, accounting and functional IT applications, but more advanced applications such as accounting programs, B2B and B2C, ERP, CRM, CAD/CAM applications are not used widely yet.

- Company sector is important determinant of IT usage of SMEs. Companies which are operating in IT sector have the highest level of IT usage compared to other sectors. However, companies in food and construction sectors have lower level of IT usage.

- IT infrastructure of the companies is an important factor determining the usage levels of internet, web page and software. As it is expected, companies having strong IT infrastructure in terms of intranet usage, web site ownership and corporate mail ownership, have higher level of internet, software and mail usage.

- Addition to the strong IT infrastructure, the number of workers, giving importance to IT training, finding more purposes to use IT, and functioning in IT sector are other important variables in explaining high level of IT usage.

- Surprisingly, company's annual giro, company age, IT usage year and number of computers used in the company do not have any effect of the IT usage level.

As conclusion, small and medium sized enterprises have been showing more concern for information technologies day by day. Despite of using IT in a basic level, they show a tendency to improve their businesses by investing on new technologies. IT infrastructure, IT training, and having more reasons to use IT, play key roles to their IT usage level. For this reason, SMEs should be motivated and supported to improve their IT infrastructure and use IT in their business activities more frequently. Additionally, more attention should be given to their IT training. All these efforts will contribute to reach the information society level.

The study has an obvious limitation, which may be addressed in the future studies. The sample was obtained from Istanbul. In order to generalize the findings for SMEs in Turkey, the sample may be collected from various cities.

\section{References}

Ang, CL., Davies, MA. and Finlay, PN. (2001), 'An Empirical Model of IT Usage in the Malaysian Public Sector,' Journal of Strategic Information Systems, 10 (2), 159174.

Bayo-Moriones, A. and Lera-Lopez, F. (2007), 'A Firm-level Analysis of Determinants of ICT Adoption in Spain,' Technovation, 27 (6-7), 352-366.

Esselaar, S., Stork, C., Ndiwalana, A. and Deen-Swarray, M. (2007), 'ICT Usage and Its Impact on Profitability of SMEs in 13 African Countries,' Information Technologies \& International Development, 4 (1), 87-100.

Kaynak, E., Tatoglu, V. and Kula, V. (2005), 'An Analysis of the Factors Affecting the Adoption of Electronic Commerce by SMEs: Evidence from An Emerging Market,' International Marketing Review, 22 (6), 623-640.

Koh, SCL. and Maguire, S. (2004), 'Identifying the Adoption of e-business and Knowledge Management within SMEs,' Journal of Small Business and Enterprise Development, 11 (3), 338-348. 
Kula, V. and Tatoglu, E. (2003), 'An Exploratory Study of Internet Adoption by SMEs in An Emerging Market Economy,' European Business Review, 15 (5), 324-333.

Kutlu, B. and Özturan, M. (2008), 'The Usage and Adoption of IT Among SMEs in Turkey: An Exploratory and Longitudinal Study,' Journal of Information Technology Management, 19 (1), 12-24.

Lohrke, FT., Franklin, GM. and FrownfelterLohrke, C. (2006), 'The Internet as an Information Conduit,' International Small Business Journal, 24 (2), 159-178.

Maguire, S., Koh, SCL. and Magrys, A. (2007), 'The Adoption of e-business and Knowledge Management in SMEs,' Benchmarking An International Journal, 14 (1), 37-58.

Matthews, P. (2007), 'ICT Assimilation and SME Expansion,' Journal of International Development, 19, 817-827.

Stansfield, M. and Grant, K. (2003), 'An Investigation into Issues Influencing the Use of the Internet and Electronic Commerce among Small-Medium Sized Enterprises,' Journal of Electronic Commerce Research, 4 (1), 15-33.

Süygün, MS. (2007), 'Determining IT Usage of Exporting SMEs in Çukurova,' Çukurova University, Social Sciences Institute, Master Thesis, Adana. 